Case Report

\title{
Management of Necrotizing Fasciitis and Fecal Peritonitis following Ostomy Necrosis and Detachment by Using NPT and Flexi-Seal
}

\author{
Fahri Yetışır, ${ }^{1}$ Akgün Ebru Şarer, ${ }^{2}$ and H. Zafer Acar ${ }^{3}$ \\ ${ }^{1}$ General Surgery Department, Atatürk Research and Training Hospital, 06800 Ankara, Turkey \\ ${ }^{2}$ Anesthesiology and Reanimation Department, Atatürk Research and Training Hospital, 06800 Ankara, Turkey \\ ${ }^{3}$ General Surgery Department, Lokman Hekim Private Hospital, 06100 Ankara, Turkey \\ Correspondence should be addressed to Fahri Yetışır; drfahriyetisir@hotmail.com
}

Received 2 July 2015; Revised 11 August 2015; Accepted 16 August 2015

Academic Editor: Boris Kirshtein

Copyright (C) 2015 Fahri Yetışır et al. This is an open access article distributed under the Creative Commons Attribution License, which permits unrestricted use, distribution, and reproduction in any medium, provided the original work is properly cited.

\begin{abstract}
Management of necrotizing fasciitis and severe faecal peritonitis following ostomy in elderly patient with comorbid disease is challenging. We would like to report management of frozen Open Abdomen (OA) with colonic fistula following ostomy necrosis and detachment in an elderly patient with comorbid disease and malignancy. 78-year-old woman with high stage rectum carcinoma was admitted to emergency department and underwent operation for severe peritonitis and sigmoid colonic perforation. Loop sigmoidostomy was performed. At postoperative 15th day, she was transferred to our clinic with necrotizing fasciitis and severe faecal peritonitis due to ostomy necrosis and detachment. Enteric effluent was removed from the OA wound by using the FlexiSeal Fecal Management System (FMS) (ConvaTec) and pesser tube in deeply located colonic fistula in conjunction with Negative Pressure Therapy (NPT). Maturation of ostomy was facilitated by using second NPT on ostomy side. After source control, delayed abdominal closure was achieved by skin flap approximation.
\end{abstract}

\section{Introduction}

More than half of all patients with intestinal stomas have complications. Complications are classified as early or late. Early complications present immediately after surgery (under a month). Ostomy necrosis and mucocutaneous dehiscence are very important early complications; they may cause major morbidity and even mortality. After ostomy, 7-25\% mucocutaneous dehiscence and 1-34\% necrosis of ostomy are reported [1]. It may be limited to one part of the ostomy or to total. If necrosis extends below the myofascial and peritoneal layers, immediate reoperation is required for stoma resection and reconstruction [1]. Nursing care is essential for keeping the subcutaneous site clean between the stoma and the skin, filling it with absorbent materials, paste, or powder depending on its depth until the new mucocutaneous junction has healed by secondary intention. In more complex cases, assisted vacuum cures have been used [2].
Open Abdomen (OA) management is a life-saving and challenging strategy in severe generalized peritonitis $[3,4]$. Mortality rates up to $50 \%$ were reported and even higher in the infected OA [5]. Enteric fistulas are one of the most devastating abdominal complications in abdominal surgery [6]. Management of OA with fistula is very challenging.

Flexi-Seal Fecal Management System (FMS) (ConvaTec) is a device which is used for bedridden or immobilized, incontinent patients with liquid or semiliquid stool. It is designed to safely and effectively contain and divert fecal matter, protect patients' wounds from fecal contamination, and reduce both the risk of skin breakdown and the spread of infection [7].

We would like to report treatment of necrotizing fasciitis and fecal peritonitis following ostomy necrosis and detachment by OA management with NPT. We would like also to emphasize, in this case, converting fistula to ostomy by the help of Flexi-Seal FMS and second NPT. 
TABLE 1: Laboratory value of patients during consultation.

\begin{tabular}{|c|c|c|c|c|c|c|c|}
\hline \multicolumn{2}{|c|}{ Biochemical analysis } & \multicolumn{2}{|c|}{ Total blood count } & \multirow[b]{2}{*}{ CRP } & \multirow[b]{2}{*}{$21 \mathrm{mg} / \mathrm{dL}(0-0.8)$} & \multicolumn{2}{|c|}{ Blood gas } \\
\hline Glu & $234 \mathrm{mg} / \mathrm{dL}$ & WBC & $18.000 \mathrm{~K} / \mu \mathrm{L}$ & & & $\mathrm{pH}$ & 7.31 \\
\hline K & $3.4 \mathrm{mmol} / \mathrm{L}$ & $\mathrm{Hb}$ & $9.8 \mathrm{~g} / \mathrm{dL}$ & INR & 1.7 & $\mathrm{pCO}_{2}$ & 38 \\
\hline $\mathrm{Alb}$ & $1.8 \mathrm{~g} / \mathrm{dL}$ & Plt & $311 \mathrm{~K} / \mu \mathrm{L}$ & Procalcitonin & $17 \mathrm{ng} / \mathrm{mL}(<0.500)$ & $\mathrm{PO}_{2}$ & 73 \\
\hline $\mathrm{LDH}$ & $211 \mathrm{U} / \mathrm{L}$ & & & & & $\mathrm{HCO}_{3}$ & 16 \\
\hline T. bilirubin & $3.4 \mathrm{mg} / \mathrm{dL}$ & & & & & $\mathrm{BE}$ & -8 \\
\hline Creatinin & $2.1 \mathrm{mg} / \mathrm{dL}$ & & & & & & \\
\hline Urea & $87 \mathrm{mg} / \mathrm{dL}$ & & & & & & \\
\hline
\end{tabular}

\section{Presentation of Case}

78-year-old woman with high stage rectum carcinoma was planned to take neoadjuvant chemoradiotherapy for down staging. During this period, she was admitted to emergency department with complaint of abdominal pain, distention, constipation, and vomiting. For last 3 days, the severity of complaints has increased. Her consciousness and orientation were also worsened. In her past history, she had hypertension, diabetes mellitus (DM), and hyperlipidemia. In physical examination, vital parameters were as follows: blood pressure (BP): 120/65 $\mathrm{mmHg}$, heart rate (HR): 86 , respiratory rate (RR): 24 , fever $(\mathrm{F}): 38^{\circ} \mathrm{C}$, and body mass index (BMI): 18. On her abdominal examination there was distention on abdomen and hyperactive bowel sounds were present. Rebound and rigidity were positive at all quadrants of abdomen. Air/fluid level was seen on abdominal X-ray film. She underwent emergent operation. At first operation, severe peritonitis and perforation of dilated sigmoid colon were seen at exploration. Curative oncological resection could not be applied, operation had to be deliberately abbreviated due to hemodynamic instability and physiologic derangement of patient, and so septic abdomen was irrigated, and loop sigmoidostomy was performed. At postoperative 7 th day, there was infective fluid coming from midline incision. After drainage and debridement, local NPT was applied to incision.

At postoperative 15th day, ostomy necrosis was identified and the patient was consulted to our clinic. Her general condition, consciousness, and orientation were not well. She was mechanically ventilated. Her vital parameters were BP: 85/50 mmHg, HR: 120, RR: 28 , F: $38^{\circ} \mathrm{C}$, and intra-abdominal pressure (IAP): $14 \mathrm{mmHg}$. She was in septic shock and mild acidosis (Table 1). SOFA score of the patient was 12 and estimated mortality was 50\% accordingly. She underwent emergent reoperation. Necrosis all around the ostomy and complete collapse with mucocutaneous detachment of ostomy were seen. Connection was present between the ostomy opening and midline incision with severe fasciitis and fecal peritonitis. Detached proximal and distal sigmoidostomy openings were seen in abdomen deeply (Figure 1). According to new modified Björck classification OA score of the patient was 4 [8]. All intra-abdominal content was irrigated with saline. Since bowel was very edematous and fragile with severe adhesion and short mesentery, these openings of ostomies could not be mobilized. New proximal end transvers colostomy was opened on right side hardly. To redirect colonic effluent to outside, Flexi-Seal was inserted

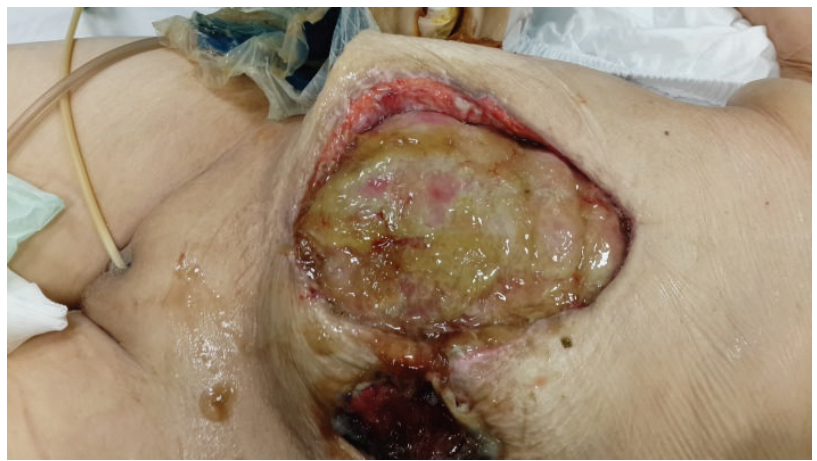

FIGURE 1: Edematous and fragile bowel with enteric fistula is seen in OA. Communication between ostomy opening and OA. Separation of ostomy from the skin and division of proximal and distal part of sigmoid colon after ostomy necrosis are seen.

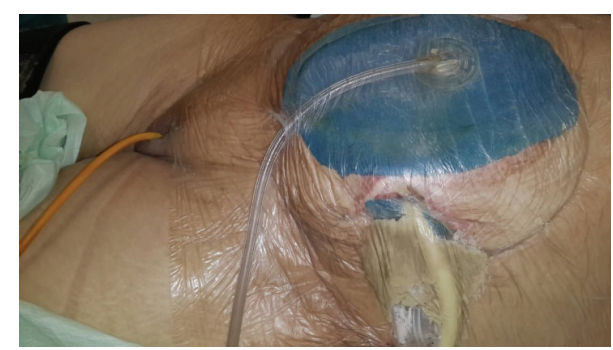

FIGURE 2: Glycerin-impregnated gauze ostomy opening, pesser drainage tube, and Flexi-Seal with applied abdominal NPT are seen.

into proximal opening of detached sigmoidostomy and pesser tube was inserted into distal opening. Glycerin-impregnated gauze was used around detached ostomy opening; pesser drainage tube and Flexi-Seal were also used to support segmentation of ostomy side from OA wound (Figure 2). Abdominal NPT was applied to OA. Low dose enteral nutrition was started at postoperative 1st day and increased day by day.

At postoperative 18th day, Flexi-Seal and pesser tube were removed from the proximal and distal colonic ends (Figure 3). Posterior parts (mesenteric side) of ostomy opening were sutured to each other to make one opening. This opening was converted to ostomy by inverting skin (Figure 4) Glycerin-impregnated gauze and ostomy paste was used over this ostomy. Two NPT systems were applied; one was 


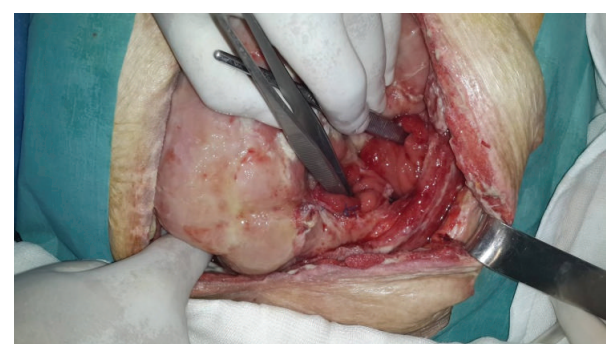

FIGURE 3: Seperated proximal and distal colonic ends are located deeply in frozen abdomen.

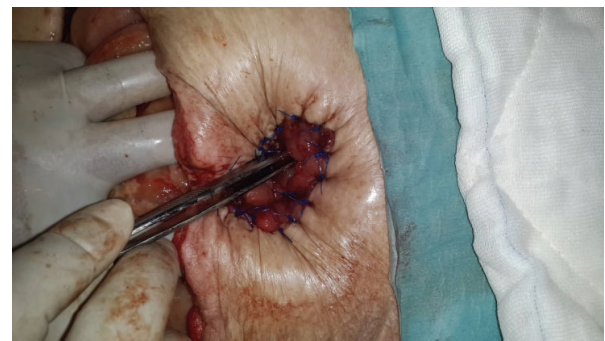

Figure 4: Performed ostomy by inverting skin is seen.

standard abdominal NPT; second one was performed on the newly created ostomy. Synchronized negative pressure was applied to both of NPTs (Figure 5) [9]. The second NPT on ostomy place was changed 3-4 times a day. Abdominal NPT was changed at 2-4 days' interval. Three days later, stoma maturation completed and second NPT application was stopped. Stoma bags could be applied.

At postoperative 23rd day, source control was achieved with two ostomies and OA wound was starting to close (Figure 6). At postoperative 38th day all OA was closed (Figure 7).

\section{Discussion}

Severe necrotizing fasciitis and fecal peritonitis due to ostomy necrosis and detachment are a rare but debating complication [1]. Predisposing factors for stoma complication are age, inflammatory bowel disease, body mass index, comorbidity, diabetes, ASA, lack of preoperative care by stoma nurse specialists, and emergent surgery. Many of these factors cannot be controlled by the surgeon but it is essential to consider that many complications are linked with the surgical technique and therefore can be prevented. In our case, an elderly patient with comorbid disease and high stage malignancy had to undergo emergent surgery. If correct diagnosis and proper treatment of ostomy complication are made timely, it can be treated with a very little cost and effort without morbidity and mortality [1].

There are lots of different systems for controlling of EAF but controlling the fistula in frozen abdomen, especially deeply localized one, is very difficult [10]. Tube VAC technique can be used for this kind of patient. The EAFs were intubated using Malecot catheters of appropriate sizes,

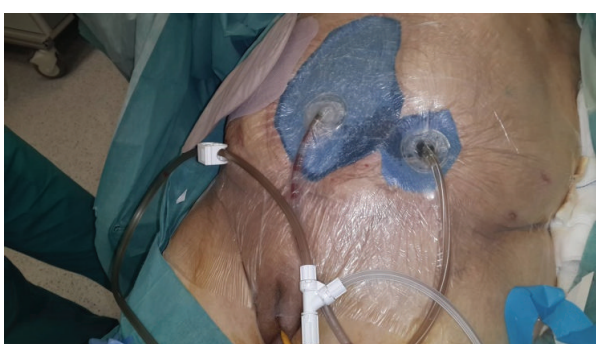

FIgURE 5: Two NPT are seen; one is abdominal NPT and second one is NPT applied on ostomy.

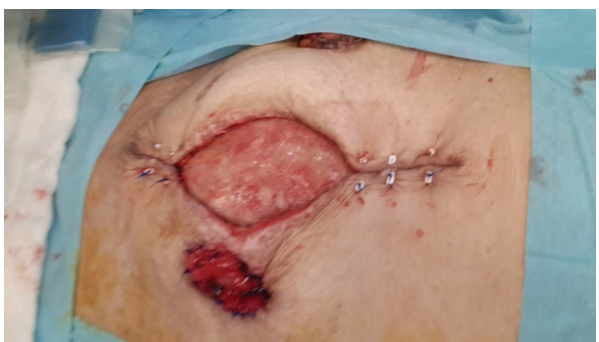

FIGURE 6: After source control was achieved, good granulation occurred and started to close step by step.

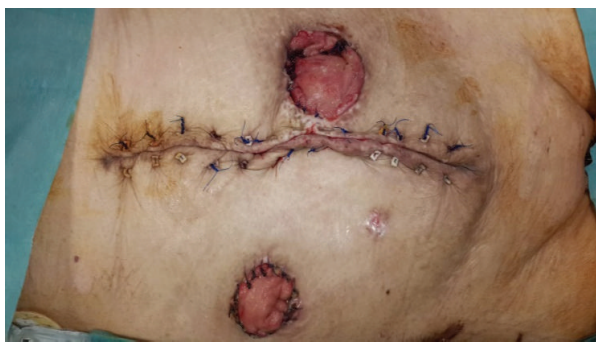

FIGURE 7: Completed closure is seen.

while the surface of the OA was covered by petroleumimpregnated gauzes and on top by a polyurethane sponge, through which the Malecot catheters were removed [11]. The Flexi-Seal device offers another alternative for effluent control. It is useful regardless of whether the enteric fistulas are low or high output and can even be useful in patients not on bowel rest. Hardwicke showed the successful continent diversion of gastrointestinal secretions in patients with EAF by the Flexi-Seal [12]. Salgado et al. reported that the FlexiSeal device serves as a valuable tool in aiding in effluent control in complex abdominal wall reconstruction in patients presenting with EAF [13]. Our EAF controlling system was similar to this system in some aspects. In our case, enteric effluent was removed from OA wound by using Flexi-Seal in deeply localized fistula in conjunction with NPT. This procedure may gain time to patient as well as to surgeon until adequate source control could be achieved. Three days after this operation, intra-abdominal sepsis and edema were resolved and these freely located intra-abdominal two colonic ends could be converted into one ostomy. 
For stoma formation, good release of the segment next to the intestine is required, for tension-free exteriorization [14]. In obese and/or in patients with short mesentery these procedures may be more difficult. Technical modifications have been described in patients with short mesenteries, such as the suture-bridge or subcutaneous bridge device [15]. Therefore, to minimize risk of retraction, an end loop colostomy has been described where the end of the closed colon remains inside the abdomen and the antimesenteric side is open as a loop colostomy [1]. In our case, there were two major gains by suturing mesenteric side of intraabdominal two free ends of sigmoidostomy. One of them was converting of the two free intra-abdominal colonic ends into one opening. Second one is to facilitate the degree of retraction due to short mesentery while making ostomy as the same mind of end loop ostomy.

There are lots of different delayed OA closure methods with NPT. One of them was skin flap approximation. This type of closure is more suitable, especially for elderly patients with comorbid disease as in our case. If only skin closure without fascial closure for delayed OA closure is performed, treatment can be terminated with less number of operations in a shorter time period.

\section{Conclusion}

For deeply localized fistula by using Flexi-Seal in conjunction with NPT, enteric effluent can be removed from OA wound. For a short time second NPT application on ostomy may facilitate ostomy maturation. Delayed abdominal closure with skin flap approximation is suitable in infected OA, especially for elderly patients with comorbid disease.

\section{Consent}

Written informed consent was obtained from the patient whose case is discussed in this paper regarding the publication of this case report and accompanying images.

\section{Conflict of Interests}

The authors have no conflict of interests.

\section{References}

[1] M. D. Miguel Velasco, F. Jiménez Escovar, and A. Parajó Calvo, "Current status of the prevention and treatment of stoma complications. A narrative review," Cirugia Espanola, vol. 92, no. 3, pp. 149-156, 2014.

[2] S. Crick, A. Roy, and C. P. MacKlin, "Stoma dehiscence treated successfully with VAC dressing system," Techniques in Coloproctology, vol. 13, no. 2, p. 181, 2009.

[3] A. E. Salman, F. Yetişir, M. Aksoy, M. Tokaç, M. B. Yildirim, and M. Kiliç, "Use of dynamic wound closure system in conjunction with vacuum-assisted closure therapy in delayed closure of open abdomen," Hernia, vol. 18, no. 1, pp. 99-104, 2014.

[4] F. Yetişir, A. Salman, F. Özdemir, D. Durak, O. Özlü, and M. Kılıç, "Modified application of dynamic wound closure system in the management of septic open abdomen," World Journal of Trauma and Critical Care Medicine, vol. 1, pp. 1-8, 2013.

[5] F. Yetişir, A. E. Salman, R. Mamedov, M. Aksoy, A. Yalcin, and C. Kayaalp, "Intrarectal negative pressure system in the management of open abdomen with colorectal fistula: a case report," International Journal of Surgery Case Reports, vol. 5, no. 3, pp. 164-168, 2014.

[6] J. J. Dubose and J. B. Lundy, "Enterocutaneous fistulas in the setting of trauma and critical illness," Clinics in Colon and Rectal Surgery, vol. 23, no. 3, pp. 182-189, 2010.

[7] A. Oguz, M. Gümüş, A. Turkoglu et al., "Fournier's gangrene: a summary of 10 years of clinical experience," International Surgery, vol. 100, no. 5, pp. 934-941, 2015.

[8] A. W. Kirkpatrick, D. J. Roberts, J. De Waele et al., "Intraabdominal hypertension and the abdominal compartment syndrome: updated consensus definitions and clinical practice guidelines from the World Society of the Abdominal Compartment Syndrome," Intensive Care Medicine, vol. 39, no. 7, pp. 1190-1206, 2013.

[9] F. Yetişir, A. E. Salman, M. Aygar, F. Yaylak, M. Aksoy, and A. Yalçin, "Management of fistula of ileal conduit in open abdomen by intra-condoit negative pressure system," International Journal of Surgery Case Reports, vol. 5, no. 7, pp. 385-388, 2014.

[10] A. Marinis, G. Gkiokas, E. Argyra, G. Fragulidis, G. Polymeneas, and D. Voros, "“Enteroatmospheric fistulae"gastrointestinal openings in the open abdomen: a review and recent proposal of a surgical technique," Scandinavian Journal of Surgery, vol. 102, no. 2, pp. 61-68, 2013.

[11] G. Al-Khoury, D. Kaufman, and A. Hirshberg, "Improved control of exposed fistula in the open abdomen," Journal of the American College of Surgeons, vol. 206, no. 2, pp. 397-398, 2008.

[12] J. Hardwicke, T. C. Wright, R. Hargest, and W. Dickson, "The use of the Flexi-Seal Faecal Management System in laparostomy wounds involving enterocutaneous fistula," Annals of the Royal College of Surgeons of England, vol. 92, no. 4, pp. W12-W14, 2010.

[13] C. J. Salgado, M. A. Serret, B. Alleyne, and A. S. Livingstone, "Flexi-seal tube use for enteric fistula control in abdominal wall reconstruction," Journal of Plastic, Reconstructive and Aesthetic Surgery, vol. 64, no. 5, pp. 698-702, 2011.

[14] P. C. Shellito, "Complications of abdominal stoma surgery," Diseases of the Colon \& Rectum, vol. 41, no. 12, pp. 1562-1572, 1998.

[15] I. Baloyiannis, G. Christodoulidis, D. Symeonidis, I. Hatzinikolaou, M. Spyridakis, and K. Tepetes, "Loop stomas with a subcutaneously placed bridge device," Techniques in Coloproctology, vol. 14, no. 1, pp. S75-S76, 2010. 


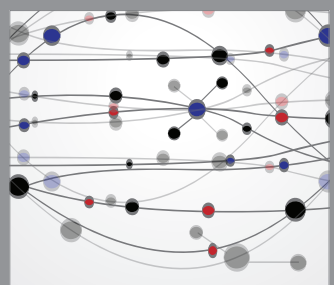

The Scientific World Journal
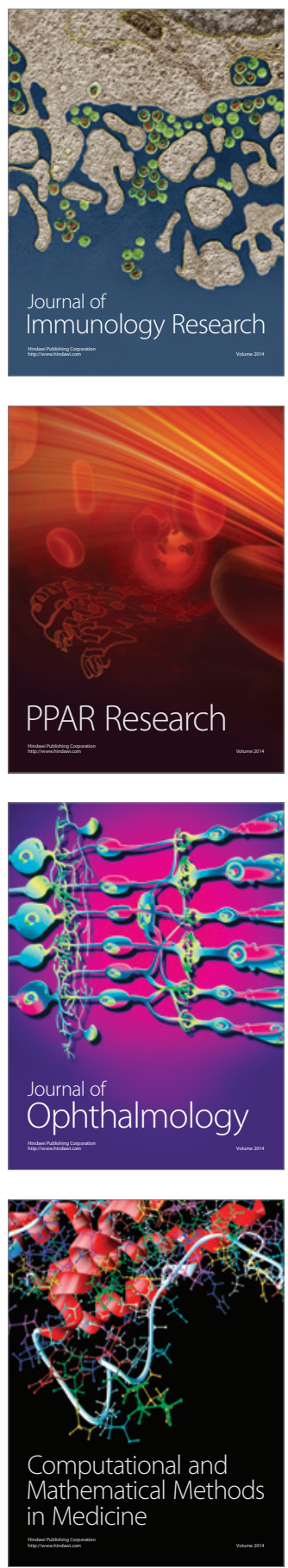

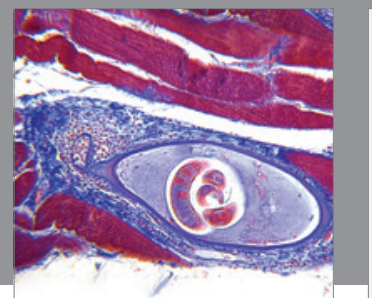

Gastroenterology

Research and Practice
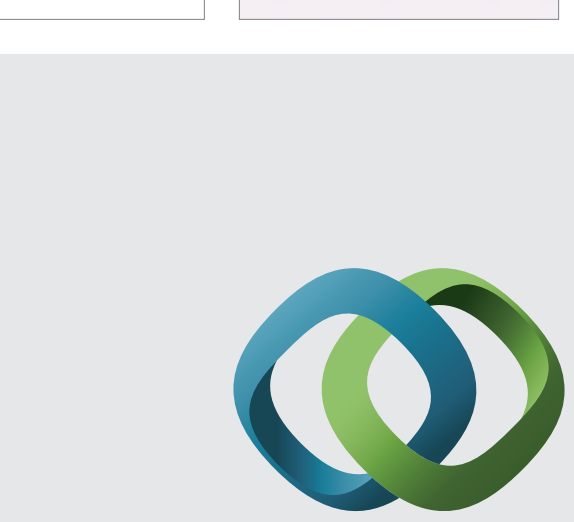

\section{Hindawi}

Submit your manuscripts at

http://www.hindawi.com
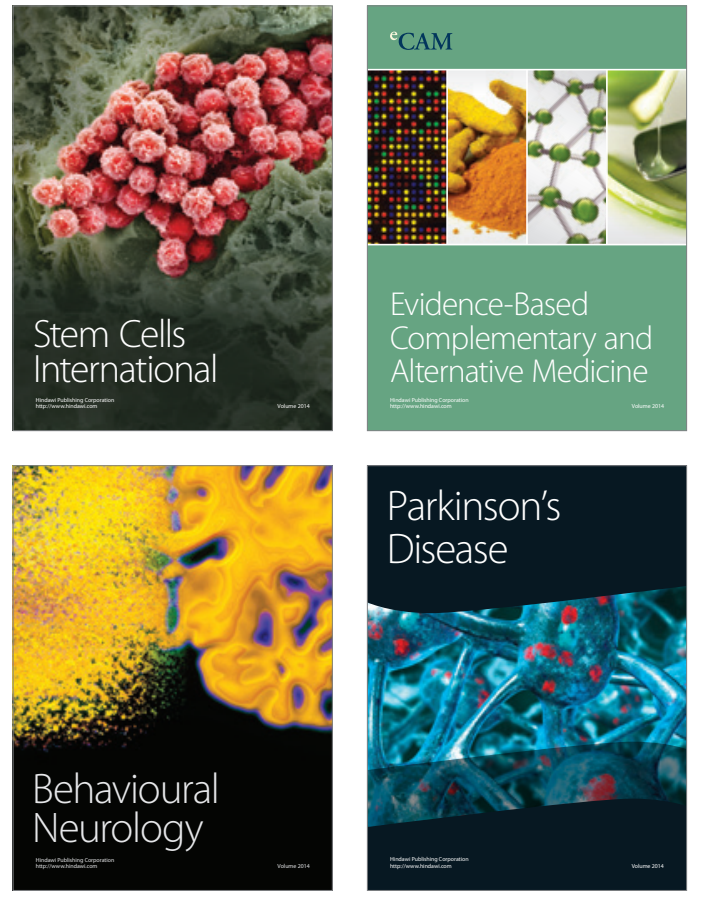
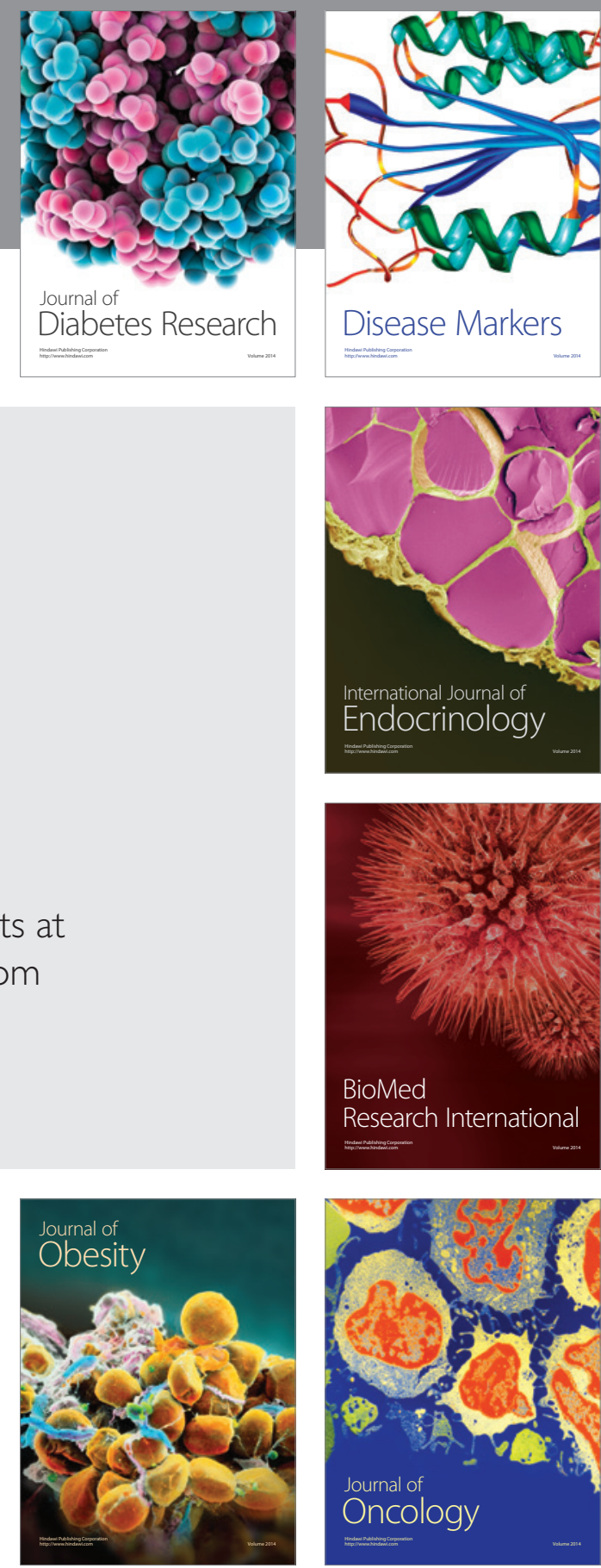

Disease Markers
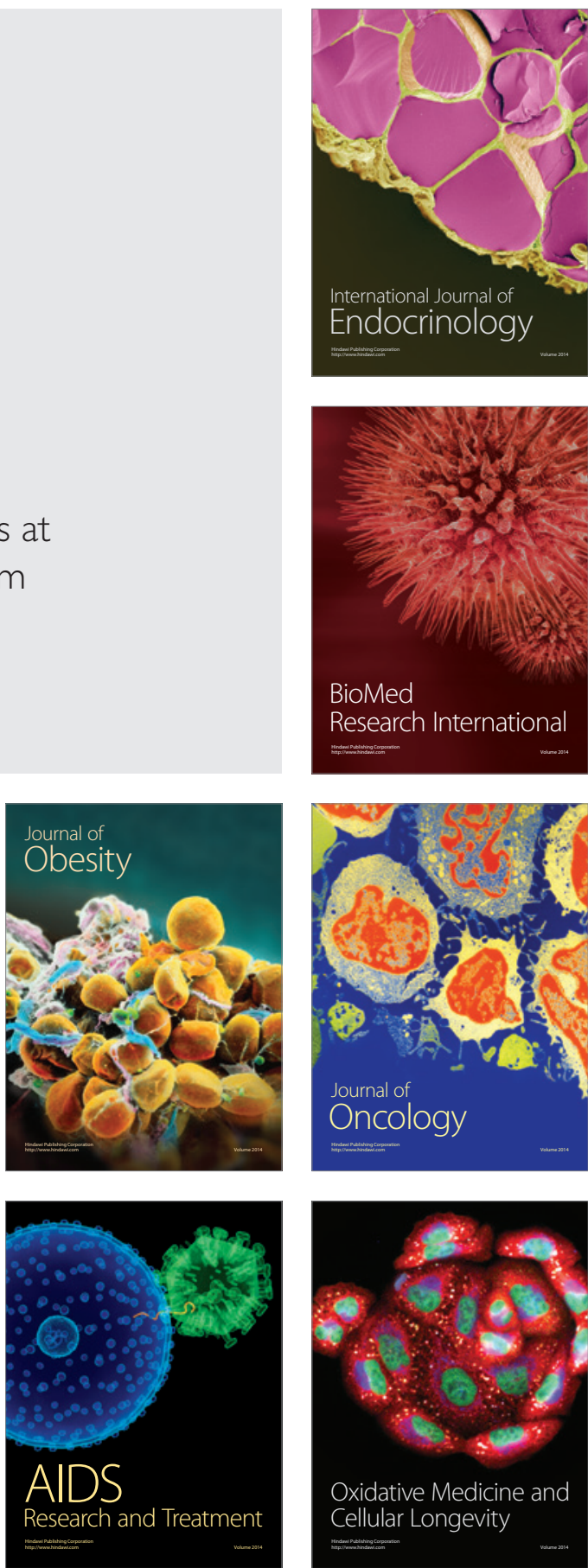